\title{
Corrosion inhibition effect of Cannabis sativa leaves extracts on N80 steel in 15\% HCl solution: Experimental, Surface and Computational studies
}

\author{
Dengdeng Zheng*, Guojie Wang
}

School of Engineering, Fujian Jiangxia University, Fuzhou, Fujian 350108, China

*E-mail: kittynew1@163.com

doi: $10.20964 / 2021.05 .33$

Received: 15 January 2021 / Accepted: 6 March 2021 / Published: 31 March 2021

The present paper reveals the corrosion inhibition estimation of Cannabis sativa (CS) extract on N80 steel in $15 \% \mathrm{HCl}$. EIS results suggests that charge transfer resistance $\left(R_{\mathrm{ct}}\right)$ increases as the CS extract increases concentration. PDP result suggests that CS extract acts as mixed type inhibitor. The result of weight loss reveals the maximum inhibition efficiency value of $97.53 \%$ at $\mathrm{g} / \mathrm{L}$. The adsorption of CS extract obeys Langmuir isotherm model. Scanning electron microscope (SEM) suggests smooth surface of N80 steel with the addition of CS extract. Density functional theory (DFT) suggests that protonated form of CS has more adsorption ability than neutral form. The Molecular dynamic simulation (MD) results suggest the higher value of adsorption energy for protonated form as compared to neutral form.

Keywords: N80 steel; HCl; Electrochemical study; DFT; MD

\section{FULL TEXT}

(C) 2021 The Authors. Published by ESG (www.electrochemsci.org). This article is an open access article distributed under the terms and conditions of the Creative Commons Attribution license (http://creativecommons.org/licenses/by/4.0/). 